ISSN: 2640-9666

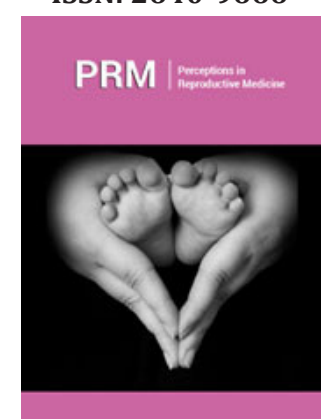

*Corresponding author: Kulvinder Kochar Kaur, India

Submission: 門 April 23, 2019

Published: 監 November 11, 2021

Volume 4 - Issue 5

How to cite this article: Kulvinder Kochar $\mathrm{K}$. The Role of Uterus from Perspective of Improving Fertility, Periconceptional Outcomes and Developmental Programming with the Concept of Developmental Origins of Health and Disease (DOHaD). Perceptions Reprod Med. 4(5). PRM. 000600. 2021.

DOI: 10.31031/PRM.2021.04.000600

Copyright@ Kulvinder Kochar K, This article is distributed under the terms of the Creative Commons Attribution 4.0 International License, which permits unrestricted use and redistribution provided that the original author and source are credited.

\section{The Role of Uterus from Perspective of Improving Fertility, Periconceptional Outcomes and Developmental Programming with the Concept of Developmental Origins of Health and Disease (DOHaD)}

\author{
Kulvinder Kochar $\mathbf{K}^{*}$ \\ India
}

\begin{abstract}
The role of uterine factor in infertility has been exemplified by better pregnancy rates found in gestational carriers even with use of donor egg IVF instead of own uteri in infertile women. Not only were PR's improved but further it was shown that even beyond window of implantation time it reduced rates of prematurity ,low birth weight and further diseases associated with defective implantation like preeclampsia and thus even fertile women need to be checked for uterine factors like fibroids endometriosis etc. and further exemplified by Fleming et al. [1]. Evans [2] \& Taylor [3] regarding role of uterine programming in long term planning of offspring even in adulthood as exemplified by rodent studies as well.
\end{abstract}

\section{Introduction}

The rates of pregnancy and associated adverse perinatal outcomes following spontaneous pregnancy are much less in contrast to pregnancies following Assisted Reproductive Technology (ART) that includes low birth weight and increased rate of preterm delivery and low birth weight. Whether this is effect of infertility, age of mother, laboratory techniques like fertilization and embryo vasculature or supraphysiological hormonal levels from ovarian stimulation is debatable. The role of uterine endometrium in success of fertility treatments has also been controversial. Some studies on donor oocyte outcomes found that uterus does not play a significant role [4-6], while others showed an increased risk of gestational diabetes, preeclampsia, abnormal placentation, with increased risk of delivery by lower segment caesarean section [7-9]. Poor endometrial receptivity with low pregnancy rates are associated with particular uterine conditions [10]. Thin endometrium, fibroids, endometriosis and adenomyosis are examples of poor endometrial receptivity with failure of conception. A lot of these are present in the infertile women, with them going undiagnosed in some of them. Once none of these defects are present, role of uterine receptivity in In Vitro Fertilization (IVF) success remains controversial, the reason being that the eggs and uterus are interlinked in most of the women who undergo IVF, which makes it difficult to find what can be attributed to egg versus endometrium in IVF success. It has been seen that oocyte donation may overcome the effect of ageing and restore fertility in women no longer developing viable eggs, but it has still been difficult to find the role of uterine related defects independently in the infertile population. It has been seen that gestational carriers have greater implantation along with clinical pregnancy and live birth rates, which gives a suggestion that uterine factors are a contributing factor in the infertile population [11-14]. 


\section{Methods}

This study was extending the work of Segal et al. [15] who studied for the first time the effect of uterine factor in an infertile population compared to healthy fertile women by seeing the outcome of oocyte donation cycles in women who used gestation carriers vis a vis their own uteri. Since all eggs used are donor eggs, differences in pregnancy rates may be attributed to the uterine environment instead of egg quality. By including large number of cycles that was available to them through the Society for Assisted Reproductive Technologies (SART) database, gave them power to differentiate the effects of uterine defects on fertility. The data that could be retrieved from SART database was pregnancy outcome, birth weight and gestational age at deliveries. They analyzed $>20,000$ donor oocyte cycles of which almost 2000 were gestational carrier cycles that resulted in>1000 deliveries, although over 18,000 were intended parent recipient cycles that resulted in $>7000$ deliveries. Patients who used a gestational carrier had a significantly greater adjusted odds ratio(aOR) of pregnancy [aOR1.33] and live birth [aOR1,37]. The results were not influenced by age adjustment ,which suggested that uterine defects are not simply a result of an aging uterus. In fertile population there is $30 \%$ to $40 \%$ increase in pregnancy rates that can be ascribed to lack of uterine implantation defects. Thus, a greater examination of the uterus/endometrial receptivity are needed critically.

Besides higher pregnancy rates in the gestational carrier cycles, there were improved outcomes of pregnancies. Among singletons the rate of prematurity got reduced associated with increased birth weights. A suggestion was got that uterine defects influence gestation much after the window of implantation. Normally poor/shallow implantation associated with defective decidualization are thought to contribute to fetal well-being, pregnancy complications and prematurity. Besides that, there is a role of uterus in developmental programming as seen by many adult health and disease related issues are impacted by fetal exposures and influenced by uterine environment [16]. Normally SART does not keep a track of long-term health outcomes which might not be clinically seen for many decades. Though the role of uterus in fetal programming affecting adult health has been well established in animal models ,the difficulty in identifying uterine defects and keeping a track of offspring over many years make this data little in humans. There is reason to believe uterine factor infertility has far greater implications than that of infertility perse. The long-term health of an individual who gestated in an impaired or defective uterus might get compromised.

\section{Conclusion}

Although the role of the uterus is now better defined in oocyte donor recipients, it is likely that the same principles probably apply to all infertility patients. Can we identify uterine defects and correct them? We can attempt to treat some like endometriosis although very resistant to treatment, hydrosalpinges, polyps and fibroids. But thin endometrium, adenomyosis and peritoneal inflammation might be more difficult to correct, however one needs to understand further how these conditions affect endometrium so that we can try to work out enhanced therapies. Thus, importance of thorough evaluation of uterine factor might not only benefit from fertility perspective but improve health outcomes in the fertility it may also help improve multiple health outcomes in the offspring.

It is thus important that when counseling for preeclampsia one should include uterine evaluation. It is possible that implantation defects are more common than are currently recognized. Infertility might probably be a representation of one of the most extreme kinds of implantation defect, in which pregnancy does not occur. Some fertile women have shallow or defective implantation instead of failed implantation. It is well recognized that defective implantation is associated with pregnancy complications and might be associated with defective fetal programming. Thus, even couples who have not presented with infertility might get a benefit from a proper uterine evaluation to avoid unwanted pregnancy complications to optimize fetal development. Further Evans et al. [2] reviewed on how development of biomarkers for prediction of uterine diseases and pregnancy disorders along with future avenues of investigation to improve fertility and enhance endometrial function.

\section{References}

1. Fleming TP, Watkins AJ, Velazquez MA, Mathers JC, Prentice AM, et al. (2018) Origins of lifetime health around the time of conception: Causes and consequences. Lancet 391(10132): 1842-1852.

2. Evans J, Salamonsen LA, Winship A, Menkhorst E, Nie G, et al. (2016) Fertile ground: Human endometrial programming and lessons in health and disease. Nat Rev Endocrinol 12(11): 654-667.

3. Taylor HS (2018) Role of the uterus in fertility ,pregnancy and developmental programming. Fertil Steril 110(5): 849-850.

4. Qin JB, Sheng XQ, Wu D, Gao SP, You YP, et al. (2017) Worldwide prevention of adverse outcomes among singleton pregnancies after invitro fertilization/intracytoplasmic sperm injection: A systematic review and meta-analysis. Arch Gynecol Obstet 295(2): 285-301.

5. Seggers J, Ponteselli M, Raveli AC, Painter RC, Halders AM, et al. (2016) Effects of in vitro fertilization and maternal characteristics on perinatal outcomes: A population-based study using siblings. Fertil Steril 105(3): 590-598.

6. Pinborg A, Wennerholm UB, Romundstad LB, Loft A, Attomaki K, et al. (2013) Why do singletons conceived after assisted reproductive technology have adverse perinatal outcomes? Systematic review and meta-analysis. Hum Reprod Update 19(2): 87-104.

7. Paulson RJ, Boostanfar R, Sadat P, Mor E, Tourgeman DE, et al. (2002) Pregnancy in the sixth decade of life: Obstetric outcomes in women of advanced age. JAMA 288(18): 2320-2323.

8. Abdalla HI, Wren ME, Thomas A, Korea L (1997) Age of the uterus does not affect pregnancy or implantation rates: A study of egg donation in women of different ages sharing oocytes from the same donor. Hum Reprod 12(4): 827-829.

9. Check JH, Jamison T, Check D, Choe JK, Brasile D, et al. (2011) Live delivery and implantation rates of donor oocyte recipients in their late forties are similar to younger recipients. J Reprod Med 56(3-4): 149-152.

10. Elenis E, Sydsjo G, Skalidou A, Lampic C, Svanberg AS (2016) Neonatal outcomes in pregnancies resulting from oocyte donation: A cohort study in Sweden. BMC Paediatr 16: 170. 
11. Le Ray C, Scherier S, Anselem O, Marzalek A, Tsatsaris V, et al. (2012) Association between oocyte donation and maternal and perinatal outcomes in women aged 43 years or older. Hum Reprod 27(3): 896901.

12. Kort DH, Gosselin J, Choi JM, Thompson MH, Goldman CJ, et al. (2012) Pregnancy after age 50: Defining risks for mother and child. Am J Perinataol 29(4): 245-250.

13. Cakmark H, Taylor HS (2011) Implantation failure: Molecular mechanisms and clinical treatment. Hum Reprod Update 17(2): 242 253.

14. Perkins KM, Boulet SL, Jamieson DJ, Kissin DM (2016) Trends and outcomes of gestational surrogacy in the United States. National
Assisted Reproductive Technology Surveillance System (NASS) Group. Fertil Steril 106(2): 435-452.

15. Segal TR, Kim K, Mumford SL, Goldfarb JM, Weineman RS (2018) How much does the uterus matter? Perinatal outcomes are improved when donor oocyte embryos are transferred to gestational carriers compared to intended parent recipients. Fertil Steril 110(5): 888-895.

16. Vannuccini S, Clifton VL, Fraser IS, Taylor HS, Critchley H, et al. (2016) Infertility and reproductive disorders: Impact of hormonal and inflammatory mechanisms of pregnancy outcome. Hum Reprod Update 22: 104-115. 